\title{
The Role of Kv1.2-Containing Potassium Channels in Serotonin- Induced Glutamate Release from Thalamocortical Terminals in Rat Frontal Cortex
}

\author{
Evelyn K. Lambe and George K. Aghajanian \\ Interdepartmental Neuroscience Program and Departments of Psychiatry and Pharmacology, Yale University School of \\ Medicine, New Haven Connecticut 06508
}

\begin{abstract}
Serotonin 5- $\mathrm{HT}_{2 \mathrm{~A}}$ receptors have been implicated in psychiatric illness and the psychotomimetic effects of hallucinogens. In brain slices, focal stimulation of $5-\mathrm{HT}_{2 \mathrm{~A}}$ receptors in rat prefrontal cortex results in dramatically increased glutamate release onto layer $\mathrm{V}$ pyramidal neurons, as measured by an increase in "spontaneous" (nonelectrically evoked) EPSCs. This glutamate release is blocked by tetrodotoxin (TTX) and is thought to involve local spiking in thalamocortical axon terminals; however, the detailed mechanism has remained unclear.

Here, we investigate parallels in EPSCs induced by either serotonin or the potassium channel blockers 4-aminopyridine (4-AP) or $\alpha$-dendrotoxin (DTX). DTX, a selective blocker of Kv1.1-, Kv1.2-, and Kv1.6-containing potassium channels, has been shown to release glutamate in cortical synaptosomes, presumably by inhibiting a subthreshold-activated, slowly inactivating potassium conductance. By comparing DTX with other potassium channel blockers, we found that the ability to induce
\end{abstract}

EPSCs in cortical pyramidal neurons depends on affinity for Kv1.2 subunits. DTX-induced EPSCs are similar to 5-HT-induced EPSCs in terms of sensitivity to TTX and $\omega$-agatoxin-IVA (a blocker of P-type calcium channels) and laminar selectivity. The involvement of thalamocortical terminals in DTX-induced EPSCs was confirmed by suppression of these EPSCs by $\mu$-opiates and thalamic lesions. More directly, DTX-induced EPSCs substantially occlude those induced by $5-\mathrm{HT}$, suggesting a common mechanism of action. No occlusion by DTX was seen when EPSCs were induced by a nicotinic mechanism. These results indicate that blockade of Kv1.2-containing potassium channels is part of the mechanism underlying 5 -HT-induced glutamate release from thalamocortical terminals.

Key words: $\mathrm{K}^{+}$; voltage-gated; dendrotoxin; 5-hydroxytryptamine; 5- $\mathrm{HT}_{2 \mathrm{~A}}$ receptor; psychedelic hallucinogens; 4-aminopyridine; prefrontal
In prefrontal cortex, serotonin (5-HT) greatly enhances glutamate release from a specific population of presynaptic terminals, as measured by an increase in "spontaneous" (nonelectrically evoked) EPSCs. Pharmacological and lesion studies have shown that this glutamate release emanates from a group of terminals originating from the thalamus (Marek et al., 2001), in particular medial dorsal, midline, and intralaminar thalamic nuclei (Berendse and Groenewegen, 1991; Öngür and Price, 2000). Such projections have been shown to be an important influence on cortical arousal with implications for attention, sleep, and affective processing of sensory stimuli (Groenewegen and Berendse, 1994). Abnormalities affecting these projections cause dysregulation of cortical activity ranging from neglect and lack of spontaneous behavior (Watson et al., 1981; Van Der Werf et al., 1999) to hallucinations, delirium, and psychosis (Serra Catafau et al., 1992; Noda et al., 1993).

Serotonin has also been implicated in cortical arousal, sensory perturbations, sleep difficulties, and psychosis through stimulation

\footnotetext{
Received June 11, 2001; revised Oct. 1, 2001; accepted Oct. 3, 2001.

The study was supported by grants from the National Institute of Mental Health (G.K.A.) and fellowships from the Bayer Foundation and the Scottish Rite (E.K.L.). This work is based on a dissertation submitted to fulfill in part the $\mathrm{PhD}$ requirements at Yale University. We thank Dr. Patricia Goldman-Rakic, Dr. Leonard Kaczmarek, and Dr. Marina Picciotto for valuable suggestions and comments. Nancy Margiotta provided excellent technical assistance.

Correspondence should be addressed to Evelyn K. Lambe, Ribicoff Research Facilities, Connecticut Mental Health Center, Room 307, 34 Park Street, New Haven, CT 06508. E-mail: evelyn.lambe@yale.edu.

Copyright (ㄷ) 2001 Society for Neuroscience $0270-6474 / 01 / 219955-09 \$ 15.00 / 0$
}

of 5- $\mathrm{HT}_{2 \mathrm{~A}}$ receptors (Vollenweider et al., 1997; Hermle et al., 1998; Oberndorfer et al., 2000). Serotonergic enhancement of cortical glutamate release is mediated by $5-\mathrm{HT}_{2 \mathrm{~A}}$ receptors (Aghajanian and Marek, 1997). It is impulse dependent and can be blocked by tetrodotoxin (TTX) (Aghajanian and Marek, 1997) and by blockers of high-voltage-activated calcium channels (Lambe and Aghajanian, 2000). Enhancement of EPSCs preferentially occurs in layer V pyramidal neurons (Lambe et al., 2000), the output neurons of prefrontal cortex, and can be induced by focal application of 5-HT along their apical dendrites (Aghajanian and Marek, 1997). The mescaline analog DOI, which selectively stimulates $5-\mathrm{HT}_{2}$ receptors, also enhances glutamate release onto these cells, especially the late component of electrically induced EPSCs (Aghajanian and Marek, 1999). Activation of $\mu$-opiate receptors suppresses 5-HT-induced glutamate release (Marek and Aghajanian, 1998), as do thalamic lesions (Marek et al., 2001). Because thalamic neuronal soma are not present in prefrontal cortex slice, 5-HT-induced glutamate release appears to result from local activation of presynaptic terminals.

Certain voltage-gated potassium $(\mathrm{Kv})$ currents are critically involved in regulating terminal excitation thresholds and firing properties, and, hence, levels of neurotransmitter release (Jan and Jan, 1989; Coetzee et al., 1999; Hille, 2001). Venom-derived neurotoxins have proved valuable for identification of such channels (Dreyer, 1990). For example, dendrotoxins are well characterized blockers of some Kv1 members that are active at rest and inactivate slowly (Harvey, 2001). Blocking these channels with $\alpha$-dendrotoxin (DTX) results in spontaneous depolarization and 


\section{A.}

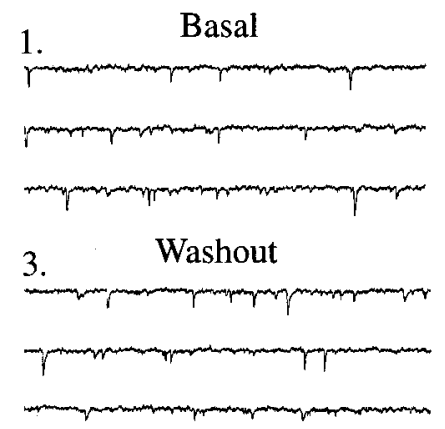

\section{B.}

Figure 1. 5-HT, 4-AP, and DTX increase the frequency and amplitude of EPSCs in layer $\mathrm{V}$ neocortical pyramidal neurons. $A$, Whole-cell recordings from one cell during baseline (1), 5-HT (2) (20 $\mu \mathrm{M}, 40 \mathrm{sec}), 5$ min washout (3), and 4-AP (4) (100 $\mu \mathrm{M}, 4 \mathrm{~min})$. $B$, Whole-cell recordings from another cell during baseline (1), 5-HT (2) (20 $\mu \mathrm{M}, 40 \mathrm{sec}$ ), $5 \mathrm{~min}$ washout (3), and DTX (4) (200 nM, $10 \mathrm{~min})$. In the right column, a portion of the sweep from the adjacent column (i.e., 5-HT, 4-AP, and DTX) has been enlarged. 5-HT was applied for $<1 \mathrm{~min}$ to prevent desensitization.
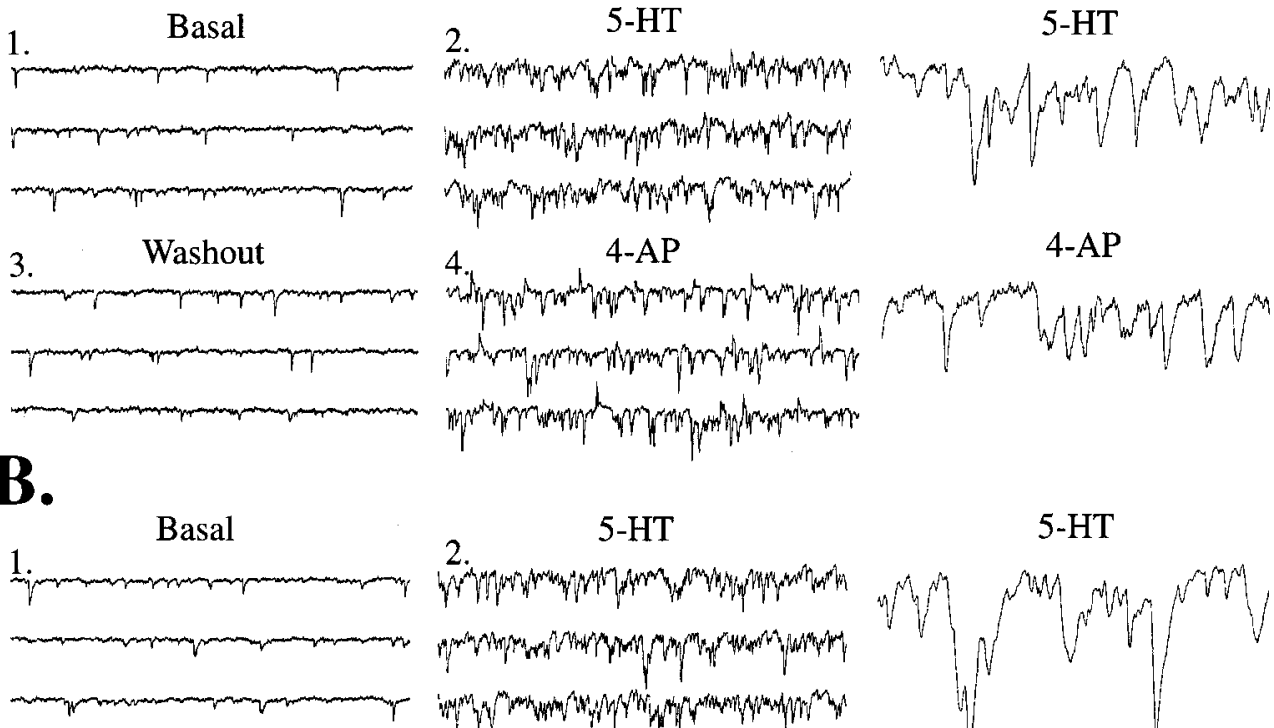

3.

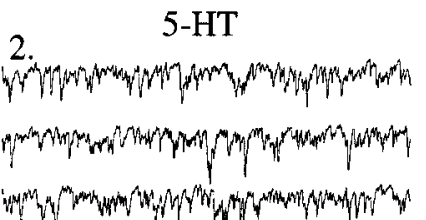

Washout

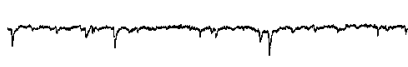

4.

DTX

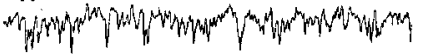

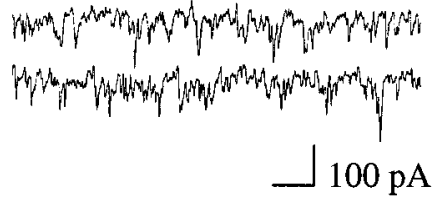
$100 \mathrm{~ms}$

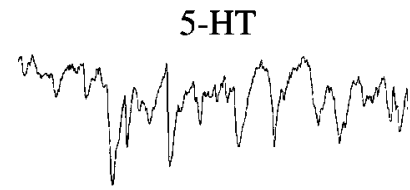

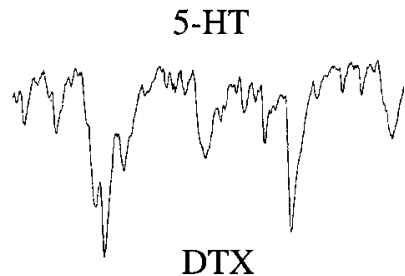

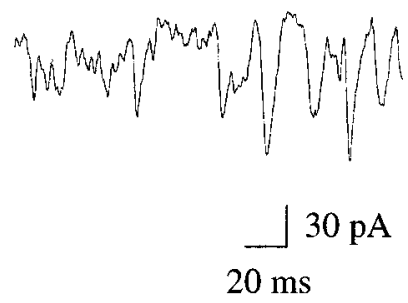

spiking in cortical synaptosomes (Tibbs et al., 1989, 1996) and certain populations of axon terminals but has little direct effect on currents in the soma of the presynaptic cell (Southan and Robertson, 1998, 2000; Bekkers and Delaney, 2001).

Here, we show that DTX mimics the effects of 5-HT by inducing EPSCs preferentially in layer V pyramidal neurons. A comparison of effects of DTX and other potassium channel blockers reveals selectivity of EPSC induction by blockers with affinity for Kv1.2 subunits. DTX-induced EPSCs meet many general tests of similarity to 5-HT-induced EPSCs. Most interestingly, however, DTX substantially occludes EPSCs induced by 5-HT, suggesting a common mechanism of action.

\section{MATERIALS AND METHODS}

Preparation of prefrontal cortical slice. Brain slices were prepared from 3to 5-week-old male Sprague Dawley albino rats, in adherence with protocols approved by the Yale University Animal Care and Use Committee. All efforts were made to minimize both the number of animals used and their suffering.

Briefly, rats were deeply anesthetized with chloral hydrate $(400 \mathrm{mg} / \mathrm{kg})$ and decapitated. Brains were quickly removed and blocked in ice-cold oxygenated modified artificial CSF (ASCF) in which sucrose $(252 \mathrm{~mm})$ is

Table 1. EPSCs induced by serotonin (20 $\mu \mathrm{M}, 40 \mathrm{sec})$, DTX (200 nM, 10 min), and 4-AP (100 $\mu \mathrm{M}, 4 \mathrm{~min})$ have similar kinetics (five cells per condition, 30 single peaks per cell)

\begin{tabular}{lll} 
Condition & $10-90$ Rise $(\mathrm{msec})$ & $\tau(\mathrm{msec})$ \\
\hline $5-\mathrm{HT}$ & $1.0 \pm 0.1$ & $2.7 \pm 0.4$ \\
DTX & $1.1 \pm 0.1$ & $2.5 \pm 0.2$ \\
4-AP & $1.1 \pm 0.1$ & $3.0 \pm 0.4$ \\
\hline
\end{tabular}

substituted for $\mathrm{NaCl}$. A 300- $\mu$ m-thick hemicoronal section was cut on a DSK microslicer (Dosaka EM, Kyoto, Japan) and transferred to the stage of a submerged recording chamber perfused with fast-flowing $(4 \mathrm{ml} / \mathrm{min})$ oxygenated, standard ACSF; the slice was secured by a fine mesh attached to a platinum wire frame. Standard ACSF was composed of (in $\mathrm{mm}$ ): $126 \mathrm{NaCl}, 3 \mathrm{KCl}, 1.25 \mathrm{NaH}_{2} \mathrm{PO}_{4}, 10$ D-glucose, $25 \mathrm{NaHCO}_{3}, 2$ $\mathrm{CaCl}_{2}$, and $2 \mathrm{MgSO}_{4}, \mathrm{pH} 7.35$.

Whole-cell recordings of EPSCs in prefrontal pyramidal neurons. Medial prefrontal pyramidal cells were selected using an Olympus BX50WI $(40 \times$ infrared lens; numerical aperture, 0.8$)$ with infrared differential interference contrast microscopy (Olympus, Melville, NY), as described by Stuart et al. (1993). Low-resistance patch pipettes (3-5 M $\Omega$ ) were pulled from Kovar glass tubing (World Precision Instruments, Sarasota, FL) using a Brown and Flaming horizontal puller (Sutter Instruments, Novato, CA) and filled with the following pipette solution (in $\mathrm{mM}$ ): 120 K-gluconate, $10 \mathrm{HEPES}, 5$ BAPTA K4, 20 sucrose, $2.38 \mathrm{CaCl}_{2}, 1 \mathrm{MgCl}_{2}$, $1 \mathrm{Na}_{2} \mathrm{ATP}$, and 0.1 Tris-GTP, pH 7.33. Somatic recordings were made in current-clamp (bridge) mode with an Axoclamp-2B amplifier (Axon Instruments, Foster City, CA) and yielded mean resting potential, spike amplitude, and input resistance values of $-72.3 \pm 3.1 \mathrm{mV}, 104.9 \pm 10.3$ $\mathrm{mV}$, and $55.7 \pm 20.2 \mathrm{M} \Omega$, respectively.

Synaptic currents were recorded using continuous single-electrode

Table 2. EPSCs induced by serotonin and DTX are suppressed to similar degrees by blockade of (1) TTX-sensitive sodium channels, (2) $\omega$-agatoxin-sensitive, high-voltage-activated calcium channels, and (3) LY293558-sensitive AMPA/kainate receptors

\begin{tabular}{lll} 
Condition & 5-HT & DTX \\
\hline TTX & $-98 \pm 2 \%$ & $-97 \pm 1 \%$ \\
$\omega$-Agatoxin IVA & $-95 \pm 1 \%$ & $-93 \pm 3 \%$ \\
LY293558 & $-99 \pm 1 \%$ & $-98 \pm 1 \%$
\end{tabular}

TTX, $2 \mu \mathrm{M}, 5 \min (n=4)$; $\omega$-agatoxin IVA, $200 \mathrm{nM}, 10 \mathrm{~min}(n=4)$; and LY293558, $3 \mu \mathrm{M}, 5 \min (n=4)$. 


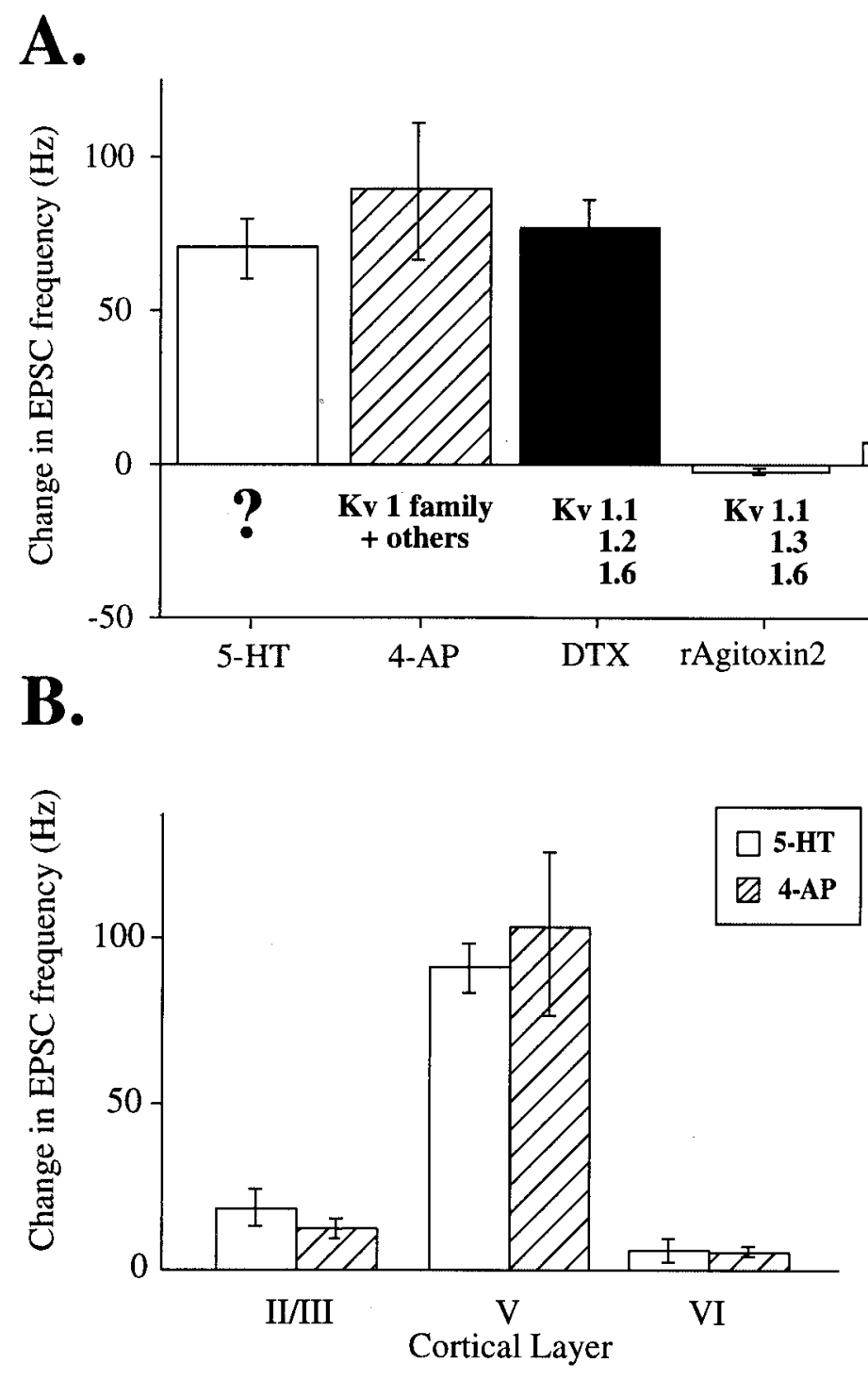

voltage-clamp mode. Neurons were held at approximately $-75 \mathrm{mV}$, and access resistance of $\leq 8 \mathrm{M} \Omega$ was maintained throughout the recording for all cells included in this study. Spontaneously occurring EPSCs were low-pass filtered at $3 \mathrm{kHz}$, amplified $100 \times$ through cyberamp, digitized at $15 \mathrm{kHz}$, and acquired using pClamp/Digidata 1200 (Axon Instruments).

Data analysis. Analysis of EPSCs from each $10 \mathrm{sec}$ block of sweeps was performed using MiniAnalysis software (Synaptosoft Inc., Decatur, GA). This program detects and measures spontaneous synaptic events according to amplitude, rise time, decay time, and area under the curve. Because of high frequency of EPSCs, the ability to accurately measure overlapping or closely occurring peaks is important for our analysis. The software uses an algorithm to detect multiple and complex peaks and automatically adjusts the baseline of closely occurring peaks using exponential extrapolation of decay. Amplitude and area thresholds were set to $8 \mathrm{pA}$ and 25-50 fC, respectively. For drug conditions, EPSCs were recorded continuously so that the $10 \mathrm{sec}$ peak period of EPSCs (for 5-HT) or a stable plateau (for DTX) could be detected. 5-HT-induced EPSCs had a rapid onset, reaching a peak at $\sim 40 \mathrm{sec}$, whereas DTX required 8-10 min before reaching a plateau. To avoid desensitization, 5-HT was applied for $<1 \mathrm{~min}$ each time. Once the peak period was noted for a specific flow rate, the same measurement period was used for all cells included in a specific experiment. For analysis of EPSC kinetics, we sampled 30 isolated single peaks of varying amplitudes from each condition, e.g., basal, 5-HT, or DTX. Time constants of decay were estimated by single-exponential curve fitting.

Radio-frequency lesions. We followed the radio-frequency lesioning procedure described by Marek et al. (2001). In brief, rats were deeply
Figure 2. $A$, Change in EPSC frequency for 5-HT and selected potassium channel blockers: 5-HT ( $20 \mu \mathrm{M}, 40 \mathrm{sec}), 4$-AP (100 $\mu \mathrm{M}, 4 \mathrm{~min})$, DTX (200 $\mathrm{nM}, 10 \mathrm{~min})$, r-agitoxin-2 (30 nM, $6 \mathrm{~min})$, toxin $\mathrm{K}(200 \mathrm{nM}, 6 \mathrm{~min})$, margatoxin ( $30 \mathrm{nM}, 6 \mathrm{~min})$, TEA ( $1 \mathrm{mM}, 6 \mathrm{~min})(n=4$ for all conditions), and $\mathrm{Ba}^{2+}(100 \mu \mathrm{M}, 6 \mathrm{~min} ; n=2)$. Potassium channel selectivity is indicated below each bar. The ability to block channels containing Kv1.2 subunits appears critical for the induction of EPSCs. $B$, Laminar differences in the response to bath application of 5-HT or 4-AP $(n=5$ per layer; order of drugs was varied, with 10 min washout in between).

anesthetized with an intraperitoneal injection of $400 \mathrm{mg} / \mathrm{kg}$ chloral hydrate and placed in a stereotaxic apparatus. An insulated stainlesssteel electrode (with $2 \mathrm{~mm}$ of tip exposed) was lowered through a small burr hole into the anterior thalamus (coordinates from bregma: $2.5 \mathrm{~mm}$ posterior, $1.2 \mathrm{~mm}$ lateral, and $6.0 \mathrm{~mm}$ depth). Unilateral lesions were made by passing $20 \mathrm{~mA}$ of current for $60 \mathrm{sec}$ using a Grass Instruments (West Warwick, RI) LM4 radio-frequency lesion maker $(100 \mathrm{kHz})$. Sham-operated rats received the same treatment; the electrode was lowered $1 \mathrm{~mm}$ short of the desired target and current was not passed. Animals were allowed a 10-14 d recovery period to allow the degeneration of thalamocortical projections. The lesions were reconstructed along mediolateral, dorsoventral, and anteroposterior dimensions using coronal sections from Paxinos and Watson (1986).

Chemicals and toxins. The following toxins were from Alomone Labs (Jerusalem, Israel): TTX, DTX, r-agitoxin-2, toxin K, r-margatoxin, and r-iberiotoxin. All other compounds, including tetraethylammonium (TEA), [D-Ala ${ }^{2}, N-M e-P^{4}{ }^{4}, \mathrm{Gly}^{5}$-ol]-enkephalin (DAMGO), and methionine enkephalin, were from Sigma (St. Louis, MO). LY293558 was a gift from Eli Lilly \& Co. (Indianapolis, IN).

\section{RESULTS}

Low concentrations of the voltage-gated potassium channel blockers DTX and 4-aminopyridine (4-AP) were found to induce EPSCs that closely resemble those induced by 5 -HT in the same cells, as shown in Figure 1. This resemblance was further char- 


\begin{tabular}{|c|c|c|c|c|c|c|c|}
\hline & Kv1.1 & $\mathrm{Kv} 1.2$ & Kv1.3 & Kv1.6 & Kv3 & BK & Kir2/3 \\
\hline 4-AP & $\mathrm{X}$ & $\mathrm{X}$ & $\mathrm{X}$ & $\mathrm{X}$ & $\mathrm{X}$ & & \\
\hline DTX & $\mathrm{X}$ & $\mathrm{X}$ & & $\mathrm{X}$ & & & \\
\hline Agitoxin & $\mathrm{X}$ & & $\mathrm{X}$ & $\mathrm{X}$ & & & \\
\hline Toxin $\mathrm{K}$ & $\mathrm{X}$ & & & & & & \\
\hline Margatoxin & & & $\mathrm{X}$ & & & & \\
\hline TEA & $\mathrm{X}$ & & & & $\mathrm{X}$ & $\mathrm{X}$ & \\
\hline $\mathrm{Ba}^{2+}$ & & & & & & & $\mathrm{X}$ \\
\hline
\end{tabular}

From Coetzee et al. (1999) and Harvey (1997).

acterized through kinetic analysis of $10-90 \%$ rise time and $63 \%$ decay time $(t)$, illustrated in Table 1. Both 5-HT- and DTXinduced EPSCs can be suppressed by fast sodium channel block with TTX (2 $\mu \mathrm{M})$, P-type, high-voltage-activated calcium channel block with $\omega$-agatoxin IVA (200 nM), and AMPA receptor block with LY293558 $(3 \mu \mathrm{M})$, as shown in Table 2 (application times and number of cells are given in the table legend). After these basic similarities had been established, additional parallels between effects of 5- $\mathrm{HT}_{2 \mathrm{~A}}$ stimulation and voltage-gated potassium channel block were explored in experiments described below.

In contrast to their consistent effects on EPSCs, postsynaptic effects of DTX and 5-HT varied. Typically, 5-HT induced $\sim 5 \mathrm{mV}$ depolarization, although small hyperpolarizations occurred in a small number of cells. After prolonged exposure, DTX induced a small postsynaptic depolarization of $\sim 3 \mathrm{mV}$ in some cells, but others showed no change in resting potential. These postsynaptic changes in membrane potential induced by either 5-HT or DTX were dissociated in time from induction of EPSCs, in most cases not beginning until $30 \mathrm{sec}$ after the onset of 5-HT-induced EPSCs and several minutes after the onset of DTX-induced EPSCs. No cell was depolarized to spike threshold by either 5-HT or DTX.

\section{Kv channel subfamily and subunit specificity}

We used several different general and specific potassium channel blockers to establish the selectivity and specificity of the ability of these agents to induce EPSCs. As shown in Figure $2 A$, only DTX and the broader-spectrum voltage-gated potassium channel blocker 4-AP (100 $\mu \mathrm{M}$; application times and number of cells are given in the figure legends) were able to induce EPSCs. TEA, a more general blocker of potassium channels, was unable to induce a significant increase in EPSCs at 0.5-3 mM. Toxins with high affinity for certain subunits of the Kv1 subfamily were tested to ascertain which were critical for the induction of EPSCs, as illustrated in Table 3. DTX, a high-affinity blocker of Kv1 channels containing Kv1.1, Kv1.2, or Kv1.6 subunits (Harvey, 1997) induced EPSCs at a level comparable with 5-HT. In contrast, r-agitoxin-2 (30 nM), a high-affinity blocker of Kv1 channels containing Kv1.1, Kv1.3, or Kv1.6 (Garcia et al., 1994), but not Kv1.2, failed to induce EPSCs. This difference suggests that the Kv1.2 subunit may be essential for the DTX-induced EPSCs we observe. Toxin K (200 nM) and r-margatoxin (30 nM), blockers of Kv1.1 and Kv1.3, respectively, failed to produce significant increases in EPSCs. Barium chloride $(100 \mu \mathrm{M})$, a blocker of inwardly rectifying potassium channels, also failed to produce significant increases in EPSCs, despite its ability to produce intermittent paroxysmal depolarizing shifts. Such shifts were not seen with 5-HT or DTX.

In another group of cells $(n=9)$, within-cell comparisons show that EPSCs induced by a stable, maximal level of DTX (200 nM, $10 \mathrm{~min})$ were significantly correlated $\left(r=0.9 ; R^{2}=0.5 ; \mathrm{df}=8\right.$; $p<0.01)$ with those induced by 5-HT (20 $\mu \mathrm{M}, 40 \mathrm{sec})$.

\section{Laminar differences in EPSC induction}

5-HT preferentially induces EPSC in layer V neurons compared with levels induced in neurons in layers II/III or VI (Lambe et al., 2000). EPSCs induced by voltage-gated potassium channel blockade and by 5 -HT were similar in neurons in each layer, as demonstrated in Figure 2B. For these experiments, 4-AP (100 $\mu \mathrm{M})$ rather than DTX was used because the former can be washed out, allowing testing of cells in multiple layers in the same slice. Both 4-AP and 5-HT preferentially induced EPSCs in layer V. In a small sample of neurons, EPSCs induced by 4-AP and DTX were compared in the different lamina: each produced a similar level of EPSCs (data not shown). This laminar specificity of EPSCs induced by DTX and low concentrations of 4-AP suggests that only a small subset of axon terminals in the cortex are affected.

\section{Suppression by $\boldsymbol{\mu}$-opioid agonists}

$\mu$-Opiates are thought to selectively inhibit glutamate release from thalamocortical terminals (Sahin et al., 1992; Delfs et al., 1994; Mansour et al., 1994; Vogt et al., 1995; Marek et al., 2001). Previously, it has been shown that $\mu$-opioid agonists markedly suppress 5-HT-induced EPSCs (Marek and Aghajanian, 1998). In the present study, the $\mu$-opiate receptor agonist DAMGO $(1 \mu \mathrm{M}$, $4 \mathrm{~min} ; n=4$ ) was shown to suppress DTX-induced EPSCs, as illustrated in Figure $3 A$. The nonselective, but quickly metabolized, opiate receptor agonist enkephalin $(100 \mu \mathrm{M})$ suppressed to a similar degree EPSCs induced by 5-HT, 4-AP, or DTX, as shown in Figure $3 B$.

\section{DTX-induced EPSCs are greatly reduced by thalamic lesions}

Previously, it has been shown that thalamic lesions markedly reduce 5-HT-induced EPSCs (Marek et al., 2001). We made unilateral radio-frequency lesions in the anterior thalamus in four animals, as illustrated in Figure 4, and performed sham operations in two animals. In slices from lesioned animals, one of nine cells showed a normal response to DTX. Cells from shamoperated animals did not differ significantly from those recorded in surgery-naïve animals. The reductions in EPSCs induced by 5-HT or DTX in the lesioned animals are shown to the right in Figure 4. It must be noted that these lesions spared some of the thalamus and hence some thalamocortical projections, so DTXinduced responses were not expected to be completely eliminated. The reduction in 5-HT-induced EPSCs is similar to that seen previously (Marek et al., 2001). The latter study showed that control lesions of the amygdala did not reduce 5-HT-induced EPSCs (Marek et al., 2001).

\section{Occlusion of 5-HT-induced EPSCs by potassium channel blockade}

To explore more directly the question of whether 5-HT and DTX induce EPSCs through a common mechanism, we used DTX to induce a stable level of EPSCs and then probed with a test pulse of 5-HT to see whether this combination was additive. If 5-HT induces EPSCs through an inhibition of Kv1.2, then DTX should be able to occlude the effects of 5-HT. Figure 5 reveals that the effects of 5-HT were substantially $(65 \%)$ occluded by DTX (200 $\mathrm{nM})$. A paired $t$ test revealed a significant difference between EPSCs induced by the combination of 5-HT and DTX and the 


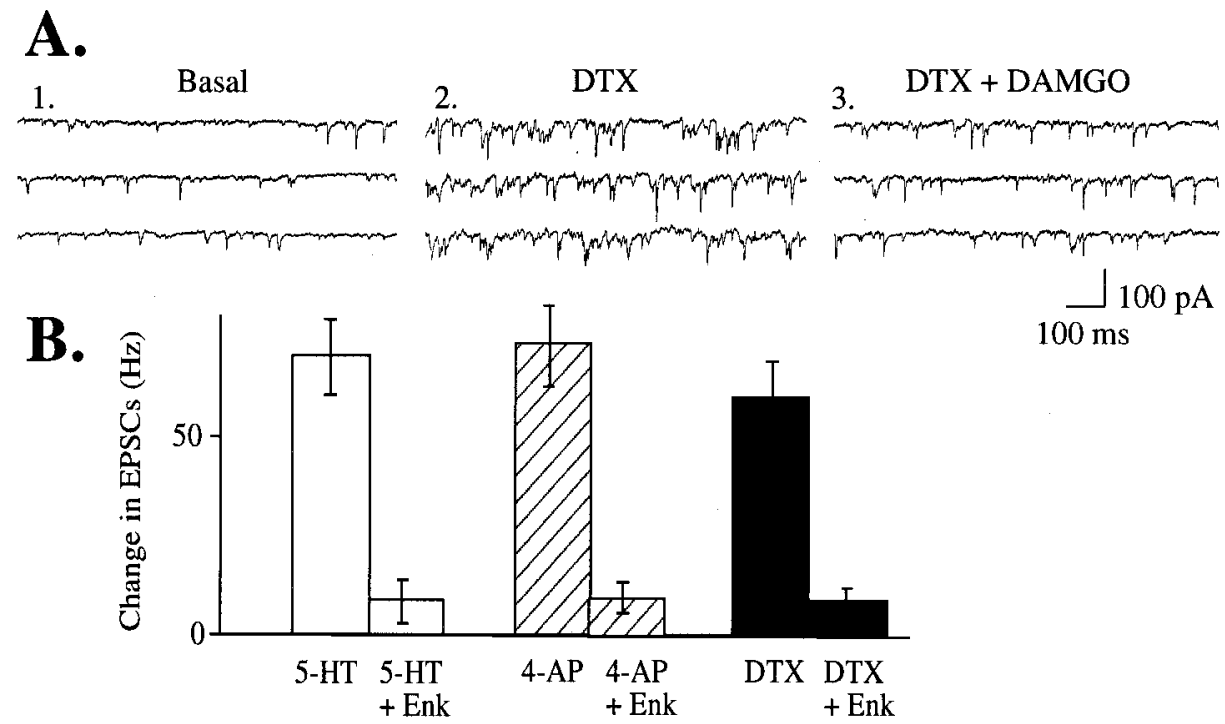

Figure 3. DTX-induced EPSCs are suppressed by $\mu$-opioid agonists. $A$, Recordings from one cell during baseline (1), DTX (2) (200 nM, $10 \mathrm{~min})$, and DAMGO (3) (1 $\mu \mathrm{M} ; 4$ min). $B$, Comparison of the ability of enkephalin $(100 \mu \mathrm{M}, 3 \mathrm{~min})$ to suppress EPSCs induced by 5 -HT, 4 -AP, or DTX $(n=5$ cells per condition).

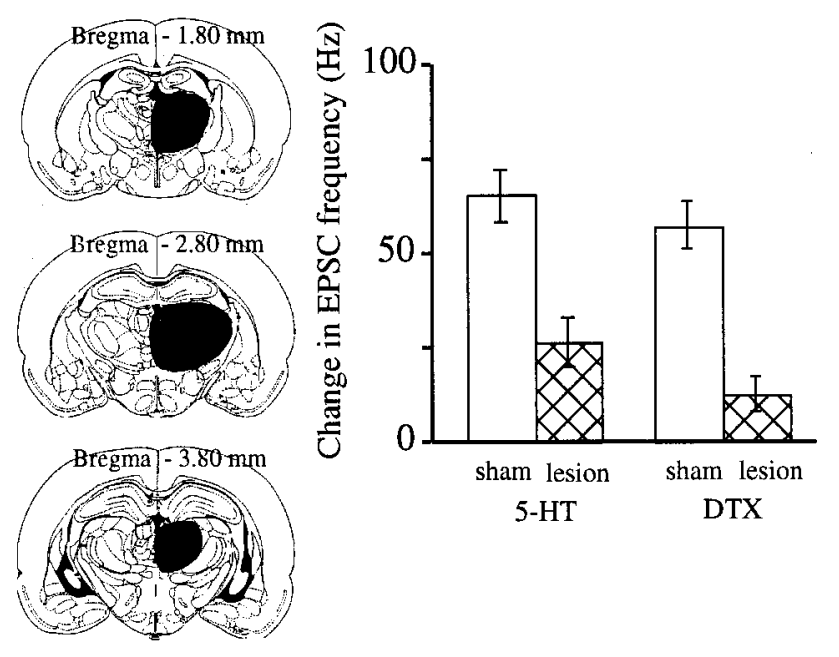

Figure 4. Unilateral radio-frequency lesions were made in the anterior thalamus, as illustrated on the left. After 10-14 d recovery to allow degeneration of thalamocortical terminals, ex vivo studies were performed in prefrontal cortex slice, and responses to 5-HT and DTX were assessed. Neurons from animals with thalamic lesions show greatly reduced EPSCs induced by either 5-HT ( $20 \mu \mathrm{M}, 40 \mathrm{sec} ; n=15)$ or DTX (200 nM, $10 \mathrm{~min}$; $n=9)$ compared with those from sham-operated or naïve animals. There were no significant differences between neurons from sham-operated $(n=$ $5)$ and surgery-naïve $(n=10)$ animals.

hypothesized additive value (paired $t$ test; $t=6.9 ; \mathrm{df}=8 ; p<$ 0.0001).

Although the lower-than-additive level of EPSCs with the combination of DTX and 5-HT looks like occlusion, there may be other reasons why the total is not additive, such as a physiological or measurement ceiling effect. To determine specificity of the occlusion of 5-HT-induced EPSCs by DTX, we took advantage of the nicotinic acetylcholine receptor as an alternative means to depolarize the thalamocortical terminals involved in the 5-HT effect (Lambe and Aghajanian, 2001). Like $\mu$-opioid binding, nicotinic binding in midcortical layers is substantially reduced after thalamic lesions and is not changed by cortical excitotoxic lesions (Sahin et al., 1992; Lavine et al., 1997), indicating that high-affinity nicotinic acetylcholine receptors in those layers are present primarily on thalamocortical terminals. Stimulation of ionotropic nicotinic acetylcholine receptors with nicotine or ace-

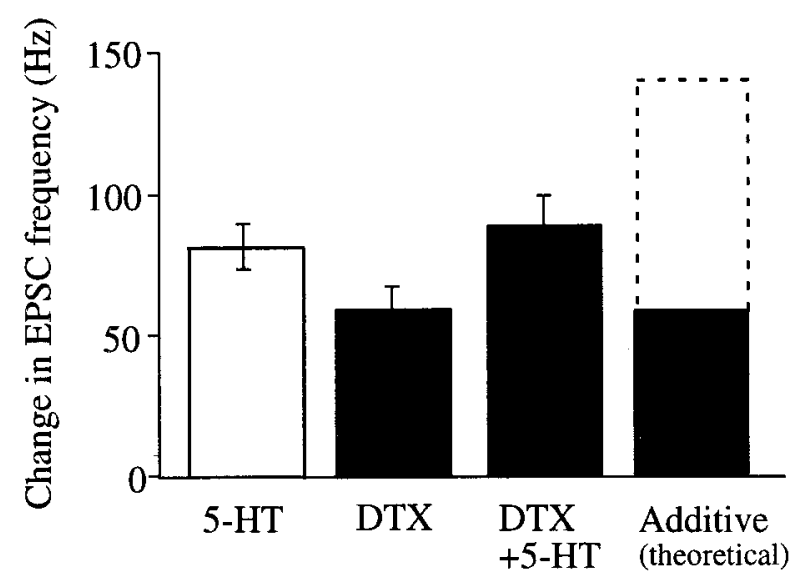

Figure 5. If 5-HT $(20 \mu \mathrm{M}, 40 \mathrm{sec})$ and DTX $(200 \mathrm{~nm}, 10 \mathrm{~min})$ induce EPSCs through different mechanisms, together their effects should be additive. Instead, the combination of 5-HT and DTX (40 sec application once plateau of DTX-induced EPSCs has been reached) is $\sim 65 \%$ occluded compared with the theoretical additive value $(n=9)$.

tylcholine (after muscarinic receptor block with atropine) results in depolarization by opening a mixed cation current instead of blocking potassium channels. Whereas DTX substantially occluded 5-HT-induced EPSCs, it failed to occlude nicotinicinduced EPSCs, as shown in Figure 6. Because the combination of DTX and nicotinic stimulation was additive, these results indicate that the occlusion of 5-HT-induced EPSCs by DTX does not represent a ceiling effect.

\section{Possible involvement of a high-voltage- or calcium- activated potassium channel}

As noted above, occlusion of the 5-HT effect by DTX was substantial but not complete. Within-cell comparisons before and during the test pulse of 5-HT in the presence of DTX $(n=9)$ showed that 5-HT induced a small but consistent increase in EPSC frequency and amplitude (paired $t$ test; $t=8.3$; df $=8 ; p<$ $0.001)$. We observed that a low concentration of TEA (500 $\mu \mathrm{M}, 1$ min), which had no effect on its own, increased the level of EPSCs from the DTX baseline to a level similar to a test pulse of 5-HT $\left(r=0.9 ; R^{2}=0.8 ; \mathrm{df}=8 ; p<0.002\right)$ and almost completely 


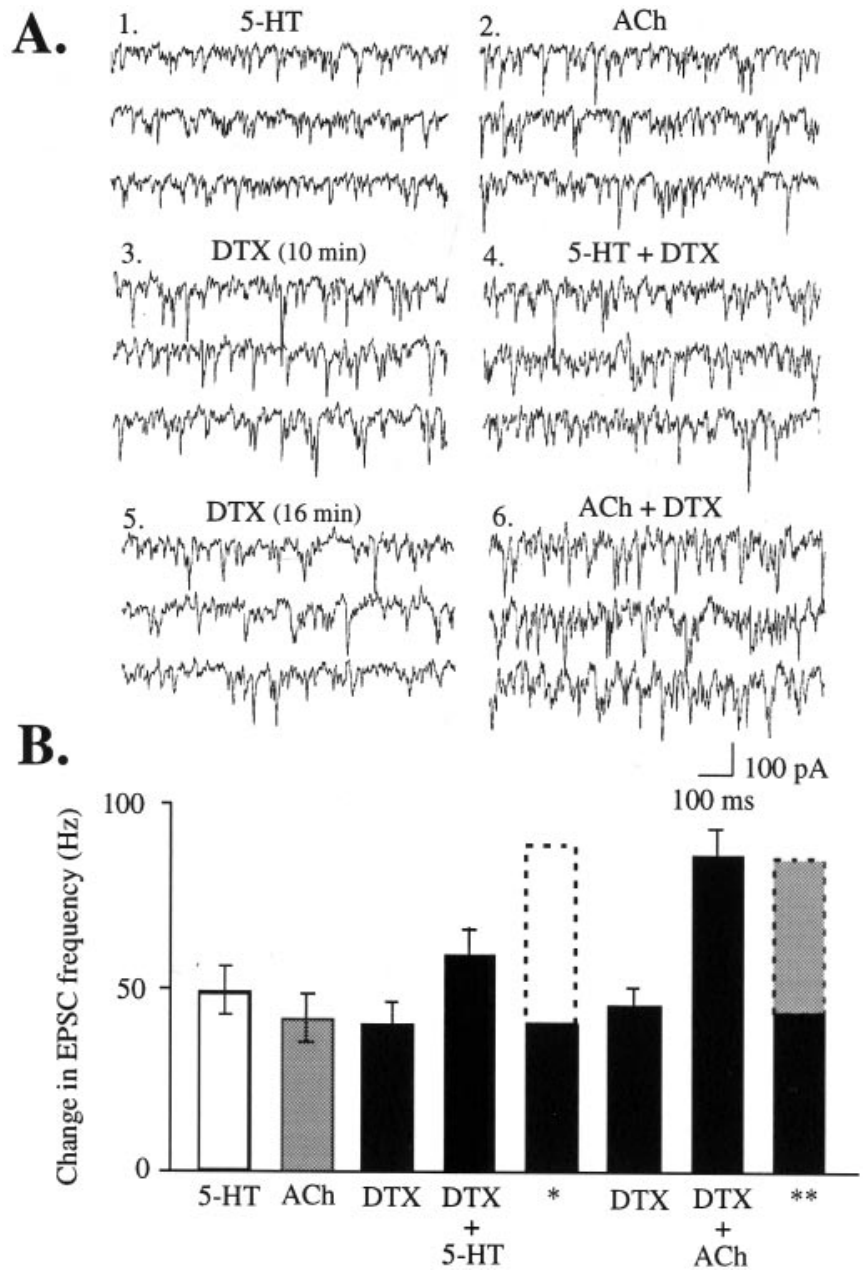

Figure 6. DTX-induced EPSCs substantially occlude those induced by 5-HT but not those induced by a different, nicotinic mechanism. These recordings were made in the presence of atropine $(0.5 \mu \mathrm{M})$ to block muscarinic activation by acetylcholine $(A C h)$. $A$, EPSCs induced by $5-\mathrm{HT}$ (1) $(20 \mu \mathrm{M}, 40 \mathrm{sec})$, ACh (2) (3 mM, $30 \mathrm{sec})$, DTX (3) (200 nM; $10 \mathrm{~min})$, the combination of DTX and 5-HT (4) (40 sec), DTX (5) (16 min), and the combination of DTX and ACh $(6)(30 \mathrm{sec})$. B. Graph of the above conditions for six cells, including the mean theoretical additive totals for DTX plus 5-HT $\left({ }^{*}\right)$ and DTX plus ACh $(* *)$. Baseline EPSC frequency ( $\sim 5-10 \mathrm{~Hz}$; data not shown) was subtracted to gives the values in the graph.

occluded $(\sim 95 \%)$ any additional increase by addition of 5 -HT, as illustrated in Figure 7.

Additional experiments are needed to discern which of the channels susceptible to block by micromolar levels of TEA may be involved. These include the large-conductance calcium-activated potassium current BK and members of the high-voltage-activated Kv3 subfamily (Coetzee et al., 1999). BK is expressed in many parts of brain (Chang et al., 1997; Wanner et al., 1999; Behrens et al., 2000), including prominent expression in thalamus (Chang et al., 1997). BK appears to be targeted to axons and nerve terminals (Knaus et al., 1996) in which it is likely involved in modulating presynaptic calcium signals and transmitter release (Robitaille and Charlton, 1992). In this study, we found that iberiotoxin (200 nM, $15 \min ; n=4)$, a selective inhibitor of BK, failed to increase EPSCs above the level of DTX alone (data not shown). However, recent studies (Behrens et al., 2000; Meera et al., 2000; Weiger et al., 2000) suggest that the bulky neuronal $\beta 4$ subunits render BK
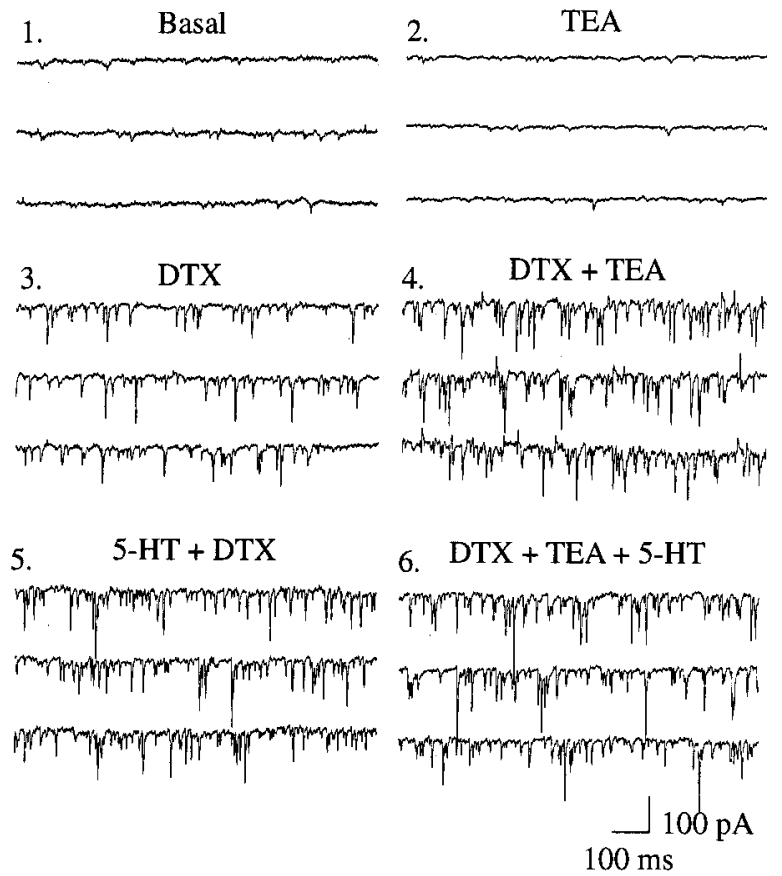

Figure 7. TEA $(500 \mu \mathrm{M})$ alone does not induce EPSCs; however, it enhances the response to DTX and further occludes the effect of 5-HT, suggesting that 5-HT may have the ability to block a TEA-sensitive potassium channel in addition to a DTX-sensitive one. EPSCs recorded during basal conditions (1), TEA (2) (500 $\mu \mathrm{M}, 1$ min), DTX (3) $(200 \mathrm{nM}$, $10 \mathrm{~min})$, the combination of DTX and TEA (4) (1 min), the combination of DTX and 5-HT (5) (1 min), and the combination of DTX, TEA, and 5-HT (6) (1 min).

insensitive to iberiotoxin. As a result, the latter agent does not provide a definitive test of the potential involvement of $\mathrm{BK}$ in 5-HT-induced EPSCs.

From an anatomical perspective, the most likely candidate would be Kv3.2. This high-voltage-activated subunit has heavy expression of mRNA in thalamus (Weiser et al., 1994). It is the only member of the Kv3 subfamily present in excitatory terminals in cortex (Chow et al., 1999). Moreover, thalamic lesions lead to marked reductions in Kv3.2 immunostaining in the midlayers of cerebral cortex, which is not affected by local excitotoxic cortical lesions (Moreno et al., 1995). However, there are no known selective blockers of this channel.

\section{DISCUSSION}

Here we describe striking similarities in kinetics, distribution, and pharmacology between 5-HT-induced EPSCs and those induced by DTX and 4-AP. These effects are specifically associated with Kv1.2 blockade and are not induced by available blockers of other Kv1 potassium channel subunits. The ability of $\mu$-opioids and thalamic lesions to substantially reduce DTX-induced EPSCs confirms that DTX is acting on thalamocortical terminals. The selective occlusion of 5-HT-induced EPSCs by DTX suggests that blockade of Kv1.2-containing potassium channels is part of the mechanism underlying 5-HT-induced glutamate release from thalamocortical terminals.

\section{Anatomical localization of DTX binding and Kv1.2}

We found that only the potassium channel blockers we tested with high affinity for Kv1.2 subunits were able to induce appreciable EPSCs, as shown in Figure 2. Wang et al. (1994) and Sheng et al. (1994) have shown that Kv1.2 antibody staining in prefrontal 


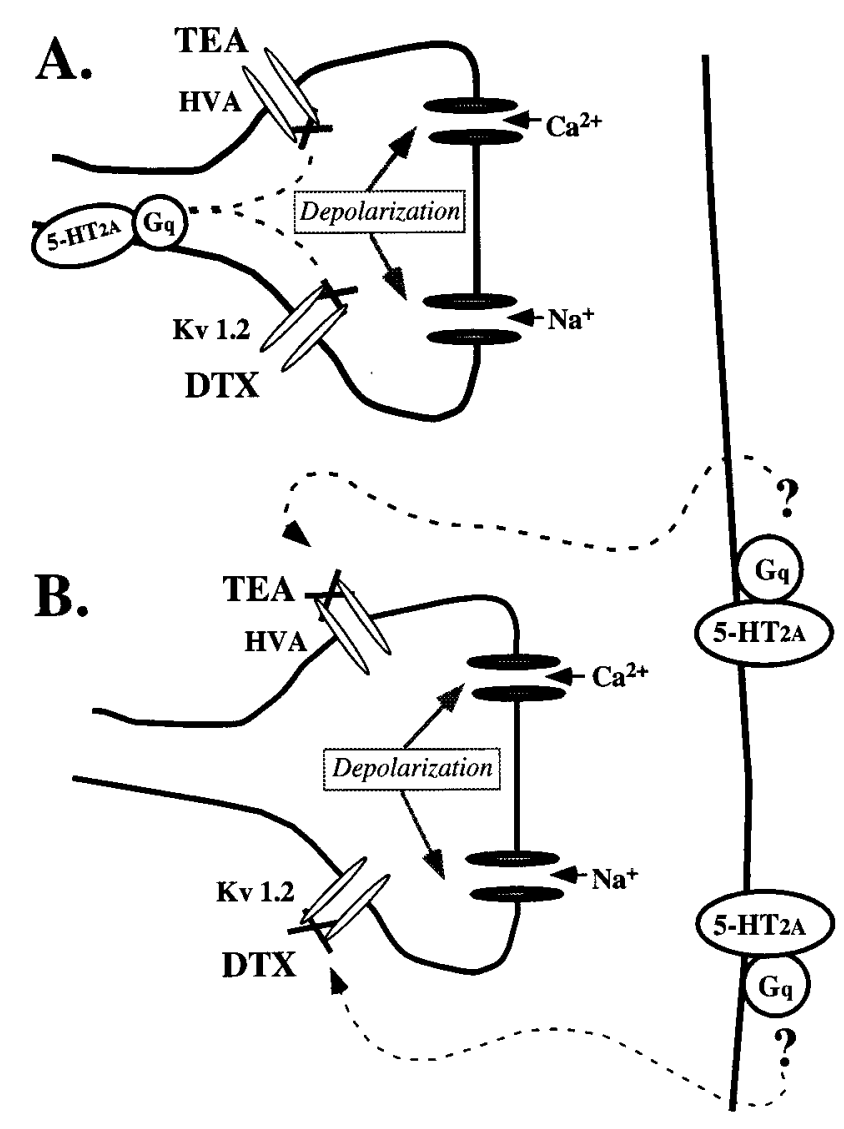

Figure 8. Models depicting two possible mechanisms for 5- $\mathrm{HT}_{2 \mathrm{~A}^{-}}$ mediated inhibition of Kv1.2-containing potassium channels, leading to TTX-sensitive glutamate release from thalamocortical terminals. As discussed previously (Aghajanian and Marek, 1999b), the 5- $\mathrm{HT}_{2 \mathrm{~A}}$ receptors responsible for inducing EPSCs could be located presynaptically or postsynaptically. A, A presynaptic model suggests that the $\mathrm{G}_{\mathrm{q}}$-coupled receptor activates an intracellular pathway capable of inhibiting both the Kv1.2-containing low-voltage-activated channel and a high-voltage- or calcium-activated potassium channel. This model could be either direct (as shown here) or indirect through an intervening excitatory interneuron, as suggested by Scruggs et al. (2000). B, A postsynaptic model suggests the ability of the $\mathrm{G}_{\mathrm{q}}$-coupled $5-\mathrm{HT}_{2 \mathrm{~A}}$ receptor to release a retrograde messenger capable of bringing about blockade or inhibition of the aforementioned potassium channels. Additional work is necessary to explore these possibilities.

cortex is heavy in the neuropil adjacent to layer $\mathrm{V}$ apical dendrites, yet conspicuously absent from the cell bodies. These studies do not agree as to whether there is Kv1.2 expression in layer V cortical neurons (Sheng et al., 1994; Wang et al., 1994). There is, however, a high level of Kv1.2 expression in thalamus (Kues and Wunder, 1992), which is congruent with our results that DTX induces glutamate release from a population of thalamocortical terminals but does not consistently depolarize cortical neurons (also shown by Bekkers and Delaney, 2001). However, it is also possible that Kv1.2-containing channels are both presynaptic and postsynaptic, and differences in the type or stoichiometry of the other subunits in the channels render these populations differentially sensitive to DTX. Several different combinations containing Kv1.2 subunits, including Kv1.2 homomers and several different heteromultimers, have been shown in homogenates of bovine and human cortex using sequential immunoprecipitation with specific Kv subunit antibodies (Shamotienko et al., 1997; Coleman et al., 1999; Wang et al., 1999). However, these studies cannot address the issue of channel subunit composition in specific cell types or the issue of preferential targeting within a certain type of neuron.

Because most toxins have been only tested for affinity to homomeric channels in expression systems, the inability of a certain toxin (i.e., toxin K) to induce EPSCs does not rule out the involvement of a particular subunit in a heteromeric channel (i.e., Kv1.1). Strikingly, Kv1.1, which has been found together with Kv1.2 subunits in axons and terminals (Monaghan et al., 2001), can be inhibited in expression systems by $\mathrm{G}_{\mathrm{q}}$-coupled 5-HT receptors (Imbrici et al., 2000).

\section{Occlusion}

The ability of DTX to occlude 5-HT induced EPSCs is consistent with 5-HT acting to block Kv1.2. However, without a positive control, a physiological or measurement ceiling effect cannot be ruled out. To ascertain the selectivity of the occlusion of 5-HT by DTX, we used nicotinic receptor stimulation as an alternative means to depolarize thalamocortical terminals affected by 5-HT and DTX (Lambe and Aghajanian, 2001). Nicotinic receptors are ionotropic and conduct a mixed cation current. The combination of DTX and acetylcholine was additive, as would be expected from depolarization through two independent mechanisms. Furthermore, the additive level of EPSCs produced by a combination of DTX and nicotinic receptor stimulation (Fig. 6) substantially exceeds that of the DTX and 5-HT combination, demonstrating that occlusion of 5-HT by DTX is not attributable to a physiological or measurement ceiling.

\section{Evidence for involvement of another channel}

Preliminary evidence suggests that adding a low concentration of TEA together with DTX further occludes the 5-HT effect, as illustrated in Figure 7. Spiking-associated blockade of channels containing Kv1.2 by DTX would normally activate high-voltageor calcium-activated potassium channels, tending to limit the period of terminal depolarization. If 5-HT blocked one or more such currents in addition to the DTX-sensitive current, it would account for the larger effect of 5-HT on glutamate release. Two possible candidates are Kv3.2, a high-voltage-activated current, and BK, a calcium- and voltage-activated conductance (see Results). Additional work is necessary to explore these possibilities.

\section{Presynaptic versus postsynaptic location of 5- $\mathrm{HT}_{2 \mathrm{~A}}$ receptors}

$5-\mathrm{HT}_{2 \mathrm{~A}}$ receptor mRNA is heavily expressed in cerebral cortex (Mengod et al., 1990). There is a dense band of 5- $\mathrm{HT}_{2 \mathrm{~A}}$ receptor binding in superficial layer $\mathrm{V}$ of prefrontal cortex (Blue et al., 1988). Immunohistochemical studies have shown a high density of $5-\mathrm{HT}_{2 \mathrm{~A}}$ receptors in apical dendrites of layer $\mathrm{V}$ pyramidal neurons (Willins et al., 1997; Hamada et al., 1998) and especially in postsynaptic densities of asymmetric terminals on apical dendrites (Hamada et al., 1998). In contrast, there is sparse $5-\mathrm{HT}_{2 \mathrm{~A}}$ receptor expression in thalamus (Mengod et al., 1990), and electron microscopy shows little or no $5-\mathrm{HT}_{2 \mathrm{~A}}$ immunoreactivity in cortical nerve terminals (Hamada et al., 1998; Jakab and Goldman-Rakic, 1998; Cornea-Hébert et al., 1999).

We showed that blockade of Kv1.2-containing voltagedependent potassium channels by DTX markedly occludes 5-HTinduced EPSCs. Models depicting two possible mechanisms for $5-\mathrm{HT}_{2 \mathrm{~A}}$-mediated inhibition of $\mathrm{Kv} 1.2$ are shown in Figure 8 (another model is suggested by Scruggs et al., 2000). The first model is based on the assumption of a presynaptic location for the $5-\mathrm{HT}_{2 \mathrm{~A}}$ receptor in which, for example, activation of the $\mathrm{G}_{\mathrm{q}}$ coupled receptor could lead to phosphorylation and inhibition of 
Kv1.2. The latter could be through the activation of a tyrosine kinase, as has been shown for $\mathrm{G}_{\mathrm{q}}$-activated Pyk2 in expression systems (Huang et al., 1993; Imbrici et al., 2000). However, recent work showing a dramatic upregulation of $5-\mathrm{HT}_{2 \mathrm{~A}}$ receptor immunostaining in the weeks after lesions of midline thalamus (Marek et al., 2001) makes a presynaptic mechanism appear unlikely. The second model in Figure 7 shows $5-\mathrm{HT}_{2 \mathrm{~A}}$ receptors located postsynaptically on layer $\mathrm{V}$ apical dendrites and suggests that their activation may release a retrograde messenger that could interact with certain voltage-gated potassium channels on presynaptic terminals. For example, $5-\mathrm{HT}_{2 \mathrm{~A}}$ receptors have been shown to stimulate phospholipase $\mathrm{A}_{2}$ (Felder et al., 1990; Kurrasch-Orbaugh et al., 2000), leading to the formation of arachidonic acid, which is an extracellular blocker of Kv1.2 homomers in expression systems and at least one member of the high-voltage-activated Kv3 family (Poling et al., 1995, 1996).

\section{Cognitive and clinical implications}

High-frequency stimulation of cortical projections from midline and intralaminar nuclei of thalamus results in a long-lasting increase in cortical arousal (Dempsey and Morison, 1942; Groenewegen and Berendse, 1994); similarly, 5- $\mathrm{HT}_{2 \mathrm{~A}}$ receptor stimulation promotes cortical arousal (Vollenweider et al., 1997; Hermle et al., 1998). During waking, 5-HT levels are five times higher than during slow-wave sleep (de Saint Hilaire et al., 2000). Increasing 5-HT at the synapse with selective serotonin reuptake inhibitors frequently results in decreases in quantity and quality of sleep, which can be prevented by cotreatment with a $5-\mathrm{HT}_{2 \mathrm{~A}}$ receptor antagonist (Oberndorfer et al., 2000). Animals placed in novel situations show increases in cortical 5-HT (Reuter and Jacobs, 1996). In humans, selective stimulation of 5- $\mathrm{HT}_{2 \mathrm{~A}}$ receptors result in hyperexcitation of frontal cortex and can produce hallucinations (Vollenweider et al., 1997, 1998).

The ability of voltage-gated potassium channel blockers to mimic $5-\mathrm{HT}_{2 \mathrm{~A}}$ activation suggests that subepileptic levels of potassium channel block may also cause increases in cortical arousal, similar to that caused by $5-\mathrm{HT}_{2 \mathrm{~A}}$ agonists. In humans, 4-AP has been shown to accelerate waking after anesthesia (Sia et al., 1982). Early reports of DTX administration to mice report hypersensitivity and hyper-reactivity to sound and touch (Harvey and Karlsson, 1980; Silveira et al., 1988). Similarly, administration of low doses of 4-AP to horses report excitation and exaggerated responses to external stimuli (Klein and Hopkins, 1981).

In this study, we showed striking parallels in modulation of glutamate release from thalamocortical terminals by either $5-\mathrm{HT}_{2 \mathrm{~A}}$ receptor stimulation or Kv1.2 voltage-gated potassium channel block. A review of the literature shows surprising similarities and interactions in the effects of voltage-gated potassium channel blockers, $5-\mathrm{HT}_{2 \mathrm{~A}}$ receptor agonists, and midline thalamic stimulation. Insight into the cellular mechanisms through which $5-\mathrm{HT}_{2 \mathrm{~A}}$ receptor agonists alter cortical arousal and information processing may provide clues about mechanisms underlying normal cortical arousal and perturbations that occur in psychosis.

\section{REFERENCES}

Aghajanian GK, Marek GJ (1997) Serotonin induces excitatory postsynaptic potentials in apical dendrites of neocortical pyramidal cells. Neuropharmacology 36:589-599.

Aghajanian GK, Marek GJ (1999) Serotonin, via 5- $\mathrm{HT}_{2 \mathrm{~A}}$ receptors, increases EPSCs in layer V pyramidal cells of prefrontal cortex by an asynchronous mode of glutamate release. Brain Res 825:161-171.

Behrens R, Nolting A, Reimann F, Schwarz M, Waldschutz R, Pongs O (2000) hKCNMB3 and hKCNMB4, cloning and characterization of two members of the large-conductance calcium-activated potassium channel $\beta$ subunit family. FEBS Lett 474:99-106.
Bekkers JM, Delaney AJ (2001) Modulation of excitability by $\alpha$-dendrotoxin-sensitive potassium channels in neocortical pyramidal neurons. J Neurosci 21:6553-6560.

Berendse HW, Groenewegen HJ (1991) Restricted cortical termination fields of the midline and intralaminar thalamic nuclei in the rat. Neuroscience 42:73-102.

Blue ME, Yagaloff KA, Mamounas LA, Hartig PR, Molliver MR (1988) Correspondence between $5 \mathrm{HT}_{2}$ receptors and serotonergic axons in rat neocortex. Brain Res 453:315-328.

Chang C-P, Dworetzky SI, Wang J, Goldstein ME (1997) Differential expression of the $\alpha$ and $\beta$ subunits of the large-conductance calciumactivated potassium channel: implication for channel diversity. Mol Brain Res 45:33-40.

Chow A, Erisir A, Farb C, Nadal MS, Ozaita A, Lau D, Welker E, Rudy $\mathrm{B}$ (1999) $\mathrm{K}^{+}$channel expression distinguishes subpopulations of parvalbumin- and somatostatin-containing interneurons. J Neurosci 19:9332-9345.

Coetzee WA, Amarillo Y, Chiu J, Chow A, Lau D, McCormack T, Moreno H, Nadal MS, Ozaita A, Pountney D, Saganich M, Vega-Saenz de Miera E, Rudy B (1999) Molecular diversity of $\mathrm{K}^{+}$channels. Ann NY Acad Sci 868:233-285.

Coleman SK, Newcombe J, Pryke J, Dolly JO (1999) Subunit composition of Kv1 channels in human CNS. J Neurochem 73:849-858.

Cornea-Hébert V, Riad M, Wu C, Singh SK, Descarries L (1999) Cellular and subcellular distribution of the serotonin 5-HT2A receptor in the central nervous system of adult rat. J Comp Neurol 409:187-209.

de Saint Hilaire Z, Orosco M, Rouch C, Python A, Nicolaidis S (2000) Neuromodulation of the prefrontal cortex during sleep: a microdialysis study in rats. NeuroReport 11:1619-1624.

Delfs JM, Kong H, Mestek A, Chen Y, Yu L, Reisine T, Chesselet M-F (1994) Expression of mu opioid receptor mRNA in rat brain: an in situ hybridization study at the single cell level. J Comp Neurol 345:46-68.

Dempsey EW, Morison RS (1942) The production of rhythmically recurrent cortical potentials after localized thalamic stimulation. Âm J Physiol 135:293-300.

Dreyer F (1990) Peptide toxins and potassium channels. Rev Physiol Biochem Pharmacol 115:93-136.

Felder CC, Kanterman RY, Ma AL, Axelrod J (1990) Serotonin stimulates phospholipase $\mathrm{A} 2$ and the release of arachidonic acid in hippocampal neurons by a type 2 serotonin receptor that is independent of inositolphospholipid hydrolysis. Proc Natl Acad Sci USA 87:2187-2191.

Garcia ML, Garcia-Calvo M, Hidalgo P, Lee A, MacKinnon R (1994) Purification and characterization of three inhibitors of voltagedependent $\mathrm{K}+$ channels from Leiurus quinquestriatus var. hebraeus venom. Biochem 33:6834-6839.

Groenewegen HJ, Berendse HW (1994) The specificity of the "nonspecific" midline and intralaminar thalamic nuclei. Trends Neurosci 17:52-57.

Hamada S, Senzaki K, Hamaguchi-Hamada K, Tabuchi K, Yamamoto H, Yamamoto T, Yoshikawa S, Okano H, Okado N (1998) Localization of 5-HT2A receptor in rat cerebral cortex and olfactory system revealed by immunohistochemistry using two antibodies raised in rabbit and chicken. Brain Res Mol Brain Res 54:199-211.

Harvey AL (1997) Recent studies on dendrotoxins and potassium ion channels. Gen Pharmacol 28:7-12.

Harvey AL (2001) Twenty years of dendrotoxins. Toxicon 39:15-26.

Harvey AL, Karlsson E (1980) Dendrotoxin from the venom of the green mamba, Dendroaspis angusticeps. Naunyn Schmiedebergs Arch Pharmacol 312:1-6.

Hermle L, Gouzoulis-Mayfrank E, Spitzer M (1998) Blood flow and cerebral laterality in the mescaline model of psychosis. Pharmacopsychiatry 31:S85-S91.

Hille B (2001) Ion channels of excitable membranes, Ed 3. Sunderland, MA: Sinauer.

Huang XY, Morielli AD, Peralta EG (1993) Tyrosine kinase-dependent suppression of a potassium channel by the $G$ protein-coupled $\mathrm{m} 1$ muscarinic acetylcholine receptor. Cell 75:1145-1156.

Imbrici P, Tucker SJ, D’Adamo MC, Pessia M (2000) Role of receptor protein tyrosine phosphatase alpha (RPTPalpha) and tyrosine phosphorylation in the serotonergic inhibition of voltage-dependent potassium channels. Pflügers Arch 441:257-262.

Jakab RL, Goldman-Rakic PS (1998) 5-Hydroxytryptamine-2A serotonin receptors in the primate cerebral cortex: possible site of action of hallucinogenic and antipsychotic drugs in pyramidal cortex apical dendrites. Proc Natl Acad Sci USA 95:735-740.

Jan LY, Jan YN (1989) Voltage-sensitive ion channels. Cell 56:13-25.

Klein L, Hopkins J (1981) Behavioral and cardiorespiratory responses to 4-aminopyridine in healthy awake horses. Am J Vet Res 42:1655-1657.

Knaus H-G, Schwarzer C, Koch RBA, Eberhart A, Kaczorowski GJ, Glossman H, Wunder F, Pongs O, Garcia ML, Sperk G (1996) Distribution of high-conductance $\mathrm{Ca}^{2+}$-activated $\mathrm{K}^{+}$channels in rat brain: targeting to axons and nerve terminals. J Neurosci 16:955-963.

Kues W, Wunder F (1992) Heterogeneous expression patterns of mammalian potassium channel genes in developing and adult rat brain. Eur J Neurosci 4:1296-1308. 
Kurrasch-Orbaugh DM, Barker EL, Nichols DE (2000) Serotonin 2 receptor agonists preferentially activate the $\mathrm{PLA}_{2}$ pathway compared to the PLC pathway. Soc Neurosci Abstr 26:534.11.

Lambe EK, Aghajanian GK (2000) Potassium channel blockers, 4-AP and $\alpha$-dendrotoxin, mimic the ability of 5-HT to induce EPSCs in layer $\mathrm{V}$ cortical pyramidal neurons. Soc Neurosci Abstr 26:721.7.

Lambe EK, Aghajanian GK (2001) Nicotinic and serotonin2A receptors enhance glutamate release from an overlapping population of thalamocortical terminals in medial prefrontal cortex. Soc Neurosci Abstr 27:259.6.

Lambe EK, Goldman-Rakic PS, Aghajanian GK (2000) Serotonin induces EPSCs preferentially in layer V pyramidal neurons of the frontal cortex in the rat. Cereb Cortex 10:974-980.

Lavine N, Reuben M, Clarke PBS (1997) A population of nicotinic receptors is associated with thalamocortical afferents in the adult rat: laminal and areal analysis. J Comp Neurol 308:175-190.

Mansour A, Fox CA, Burke S, Meng F, Thompson RC, Akil H, Watson SJ (1994) Mu, delta, and kappa opioid receptor mRNA expression in the rat CNS: an in situ hybridization study. J Comp Neurol 350:412-438.

Marek GJ, Aghajanian GK (1998) 5-Hydroxytryptamine-induced excitatory postsynaptic currents in neocortical layer V pyramidal cells: suppression by $\mu$-opiate receptor activation. Neuroscience 86:485-497.

Marek GJ, Wright RA, Gewirtz JC, Schoepp DD (2001) A major role for thalamocortical afferents in serotonergic hallucinogen receptor function in neocortex. Neuroscience 105:379-392.

Meera P, Wallner M, Toro L (2000) A neuronal $\beta$-subunit (KCNM4) makes the large conductance, voltage- and $\mathrm{Ca}^{2+}$-activated $\mathrm{K}^{+}$channel resistant to charybdotoxin and iberiotoxin. Proc Natl Acad Sci USA 97:5562-5567.

Mengod G, Pompeiano M, Martinez-Mir MI, Palacios JM (1990) Localization of the mRNA for the 5-HT2 receptor by in situ hybridization histochemistry. Correlation with the distribution of receptor sites. Brain Res 524:139-143.

Monaghan MM, Trimmer JS, Rhodes KJ (2001) Experimental localization of Kv1 family voltage-gated $\mathrm{K}^{+}$channel $\alpha$ and $\beta$ subunits in rat hippocampal formation. J Neurosci 21:5973-5983.

Moreno H, Kentros C, Bueno E, Weiser M, Hernandez A, Vega-Saenz de Miera E, Ponce A, Thornhill W, Rudy B (1995) Thalamocortical projections have a $\mathrm{K}^{+}$channel that is phosphorylated and modulated by cAMP-dependent protein kinase. J Neurosci 15:5486-5501.

Noda S, Mizoguchi M, Yamamoto A (1993) Thalamic experiential hallucinosis. J Neurol Neurosurg Psychiatry 56:1224-1226.

Oberndorfer S, Saletu-Zyhlarz G, Saletu B (2000) Effects of selective serotonin reuptake inhibitors on objective and subjective sleep quality. Neuropsychobiology 42:69-81.

Öngür D, Price JL (2000) The organization of networks within the orbital and medial prefrontal cortex of rats, monkeys, and humans. Cerebral Cortex 10:206-219.

Paxinos G, Watson C (1986) The rat brain in stereotaxic coordinates. Ed 2. New York: Academic.

Poling JS, Karanian JW, Salem JN, Vincini S (1995) Time- and voltagedependent block of delayed rectifier potassium channels by docosahexaenoic acid. Mol Pharmacol 47:381-390.

Poling JS, Rogawski MA, Salem JN, Vincini S (1996) Anandamide, an endogenous cannabinoid, inhibits Shaker-related voltage-gated $\mathrm{K}^{+}$ channels. Neuropharmacology 35:983-991.

Reuter LE, Jacobs BL (1996) A microdialysis examination of serotonin release in the rat forebrain induced by behavioral/experimental manipulations. Brain Res 739:57-69.

Robitaille R, Charlton MP (1992) Presynaptic calcium signals and transmitter release are modulated by calcium-activated potassium channels. J Neurosci 12:297-305.

Sahin M, Bowen WD, Donoghue JP (1992) Location of nicotinic and muscarinic cholinergic and $\mu$-opiate receptors in rat cerebral neocortex: evidence from thalamic and cortical lesions. Brain Res 579:135-147.

Scruggs JL, Patel S, Bubser M, Deutch AY (2000) DOI-induced activation of the cortex: dependence on $5-\mathrm{HT}_{2 \mathrm{~A}}$ heteroreceptors on thalamocortical glutamatergic neurons. J Neurosci 20:8846-8852.
Serra Catafau J, Rubio F, Peres Serra J (1992) Peducular hallucinosis associated with posterior thalamic infarction. J Neurol 239:89-90.

Shamotienko OG, Parcej DN, Dolly JO (1997) Subunit combinations defined for $\mathrm{K}+$ channel Kv1 subtypes in synaptic membranes from bovine brain. Biochem 36:8195-8201.

Sheng M, Tsaur M-L, Jan YN, Jan LY (1994) Contrasting subcellular localization of the $\mathrm{Kv} 1.2 \mathrm{~K}^{+}$channel subunit in different neurons of rat brain. J Neurosci 14:2408-2417.

Sia RL, Boonstra S, Westra P, Haenen HT, Wesseling H (1982) An electroencephalographic study of 4-aminopyridine. Anesth Analg 61:354-357.

Silveira R, Barbeito L, Dajas F (1988) Behavioral and neurochemical effects of intraperitoneally injected dendrotoxin. Toxicon 26:287-292.

Southan AP, Robertson B (1998) Patch-clamp recordings from cerebellar basket cell bodies and their presynaptic terminals reveal an asymmetric distribution of voltage-gated potassium channels. J Neurosci 18:948-955.

Southan AP, Robertson B (2000) Electrophysiological characterization of voltage-gated $\mathrm{K}^{+}$currents in cerebellar basket and Purkinje cells: Kv1 and Kv3 channel subfamilies are present in basket cell nerve terminals. J Neurosci 20:114-122.

Stuart GJ, Dodt HU, Sakmann B (1993) Patch-clamp recordings from the soma and dendrites of neurons in brain slices using infrared video microscopy. Pflügers Arch 423:511-518.

Tibbs GR, Dolly JO, Nicholls DG (1989) Dendrotoxin, 4-aminopyridine, and $\beta$-bungarotoxin act at common loci but by two distinct mechanisms to induce $\mathrm{Ca}^{2+}$-dependent release of glutamate from guinea-pig cerebrocortical synaptosomes. J Neurochem 52:201-206.

Tibbs GR, Dolly JO, Nicholls DG (1996) Evidence for the induction of repetitive action potentials in synaptosomes by $\mathrm{K}^{+}$-channel inhibitors: an analysis of plasma membrane ion fluxes. J Neurochem 67:389-397.

Van Der Werf YD, Weerts JGE, Jolles J, Witter M, Lindeboom J, Scheltens P (1999) Neuropsychological correlates of a right unilatera lacunar thalamic infarction. J Neurol Neurosurg Psychiatry 66:36-42.

Vogt BA, Wiley RG, Jensen EL (1995) Localization of mu and delta opioid receptors to anterior cingulate afferents and projection neurons and input/output model of mu regulation. Exp Neurol 135:83-92.

Vollenweider FX, Leenders KL, Scharfetter C, Maguire P, Stadelmann O, Angst J (1997) Positron emission tomography and fluorodeoxyglucose studies of metabolic hyperfrontality and psychopathology in the psilocybin model of psychosis. Neuropsychopharmacology 16:357-372.

Vollenweider FX, Vollenweider-Scherpenhuyzen MFI, Babler A, Vogel H, Hell D (1998) Psilocybin induces schizophrenia-like psychosis in humans via a serotonin-2 agonist action. NeuroReport 9:3897-3902.

Wang FC, Parcej DN, Dolly JO (1999) a Subunit compositions of Kv1.1containing $\mathrm{K}^{+}$channel subtypes fractionated from rat brain using dendrotoxins. Eur J Biochem 263:230-237.

Wang H, Kunkel DD, Schwartzkroin PA, Tempel BL (1994) Localization of Kv1.1 and Kv1.2, two K channel proteins, to synaptic terminals, somata, and dendrites in the mouse brain. J Neurosci 14:4588-4599.

Wanner SG, Koch RO, Koschak A, Trieb M, Garcia ML, Kaczorowski GJ, Knause H-G (1999) High-conductance calcium-activated potassium channels in rat brain: pharmacology, distribution, and subunit composition. Biochemistry 38:3392-3400.

Watson RT, Valenstein E, Heilman KM (1981) Thalamic neglect: possible role of the medial thalamus and nucleus reticularis in behavior. Arch Neurol 38:501-506.

Weiger TM, Holmqvist MH, Levitan IB, Clark FT, Sprague S, Huang W-J, Ge P, Wang C, Lawson D, Jurman ME, Glucksmann MA, Silos-Santiago I, DiStefano PS, Curtis R (2000) A novel nervous system $\beta$-subunit that downregulates human large conductance calciumdependent potassium channels. J Neurosci 20:3563-3570.

Weiser M, Vega-Saenz de Miera E, Kentros C, Moreno H, Franzen L, Hillman D, Baker H, Rudy B (1994) Differential expression of Shawrelated $\mathrm{K}^{+}$channels in the rat central nervous system. J Neurosci 14:949-972

Willins DL, Deutch AY, Roth BL (1997) Serotonin 5- $\mathrm{HT}_{2 \mathrm{~A}}$ receptors are expressed on pyramidal cells and interneurons in the rat cortex. Synapse 27:79-82. 